\title{
Genetic structuring in farmed and wild Gilthead seabream and European seabass in the Mediterranean Sea: implementations for detection of escapees
}

\author{
Eirini-Slavka Polovina ${ }^{1}$, Evelina Kourkouni ${ }^{1}$, Costas S. Tsigenopoulos ${ }^{2}$, Pablo Sanchez-Jerez ${ }^{3}$ \\ and Emmanuel D. Ladoukakis ${ }^{1, *}$ \\ ${ }^{1}$ Department of Biology, University of Crete, Iraklio, Greece \\ 2 Institute of Marine Biology, Biotechnology and Aquaculture, Hellenic Centre for Marine Research, Iraklio, Greece \\ ${ }^{3}$ Department of Marine Sciences and Applied Biology, Universitat d'Alicante, Alicante, Spain
}

Received 23 October 2019 / Accepted 4 June 2020

Handling Editor: Roman Wenne

\begin{abstract}
Microsatellite markers were used to investigate the genetic structure of the two most important cultured fish in the Mediterranean Sea, the gilthead seabream (Sparus aurata) and the European seabass (Dicentrarchus labrax), from two (one wild and one farmed) populations in Western Mediterranean (Spain) and from two (one wild and one farmed) populations Eastern Mediterranean (Greece). All populations were in Hardy-Weinberg disequilibrium. Interestingly, wild and farmed populations for both species from Greece were genetically differentiated and could be distinguished from each other. We used Bayesian methods for cluster analysis of farmed and wild populations. Our analysis has implications for the identification of escapees from fish farms to the wild.
\end{abstract}

Keywords: Seabream / seabass / genetic structure / escapees

\section{Introduction}

Gilthead sea bream (Sparus aurata) and European sea bass (Dicentrarchus labrax) are the two most important species for finfish aquaculture in the Mediterranean Sea. Both species are found in the Mediterranean Sea and in the eastern North Atlantic, with the European sea bass having a more northward distribution up to Norway. They support commercial fisheries in some areas, and are well-established as aquaculture species, particularly in the Mediterranean Sea. The two species are usually reared in the same structures and the same farms. The majority of the fish reared in Europe are maintained in floating sea cages, into near shore locations, although few farms in Spain and Italy are using salt marshes to produce fish in ponds (ICES, 2006). With the global number of cultured fish being in a very high proportion compared to the wild populations (mainly in areas where fish farms are located, a high number of escapees might have the potential to lead to displacement of wild population in some specific sites. This is the reason why mitigation strategies based on sound scientific criteria in relation to both species need to be prepared and rapidly taken into consideration. ICES (2015) suggests that for

*Corresponding author: ladoukakis@uoc.gr these two non-highly migratory fish species with small localized populations, studies seem to be of particular importance to consider the status of the natural stocks in the area, the potential genetic, trophic and behavioral interactions, and, foremost and specifically, the development of methods for recovery of escaped fish in the event of largescale escapements.

Depending on the strategy of the fish farms to manage their broodstocks, farmed populations are expected to differ from the local natural populations for three main reasons. First, breeders may be wild-caught fish, according to a common practice for re-stocking the farms. These breeders represent a small sub-sample of the wild population, thus farmed stocks are expected to contain less diversity than the wild ones. This has been observed in several species, such as salmon (Norris et al., 1999; Skaala et al., 2004), seabream (Karaiskou et al., 2009; Loukovitis et al., 2011) and sea trout (Bernas et al., 2020) (but see de Oliveira et al., 2018). Second, in some cases, farms located in different geographic regions exchange fry and the farmed fish have different genetic backgrounds from the wild fish outside cages. For instance, due to increased demand for juveniles (fingerlings) in the Eastern Mediterranean countries (Greece, Turkey and Croatia), there are often imports of fry from the Western Mediterranean countries such as France and Spain (Barazi-Yeroulanos, 2010; Segvic-Bubic 
et al., 2011). Finally, various programs of selective breeding already in place for multiple consecutive generations, might reduce in the long term the heterozygosity of the farmed compared to the wild populations (for example see D’Ambrosio et al., 2019).

Due to technical or operational failures, farmed fish can escape in natural environment (Dempster et al., 2007). The impact of escaping fish to local populations has not been assessed in detail and there are different lines of evidence, which suggest that escapees might have important effects on native populations (Arechavala-Lopez et al., 2018). A potential escaping event entails the risk of genetic admixture of local populations with fish from the aquaculture facilities. The foreign DNA can genetically blight local wild gene pool and damage local adaptations which have been reported in many fish species, even under high gene flow (see Barth et al., 2017). For example, farmed fish strains can be genetically different from the wild populations in traits such as growth rate, physiology, and behaviour (Glover, 2010). Then, the hybrids from crosses between farmed and wild fish can have lower fitness than the wild fish in natural environments, as it has been reported in several cases (McGinnity et al., 1997; Fleming et al., 2000; McGinnity et al., 2003; Reed et al., 2015; Skaala et al., 2019). It has been reported that gilthead sea bream escapees can survive successfully to the natural environment posing a risk of hybridization with individuals from the wild (Segvic-Bubic et al., 2018). The risk from this genetic contamination has not yet been fully assessed (Yang et al., 2019).

Identifying the escapees could be an efficient approach for mitigating the effects of genetic admixture of farmed with wild populations. Such identification has been applied by using physical marking of the farmed fish with tags (Glover, 2010). This method is prohibitively expensive and has animal welfare concerns. An alternative method which has been used for salmon, Atlantic cod and rainbow trout is the identification of escapees using the DNA-stand-by method (Glover, 2010). This method assigns an individual to a certain population - in this case farmed or wild - according to its genetic profile. The genetic profile of the individuals is usually retrieved using genetic markers such as microsatellites, AFLPs and single nucleotide polymorphisms (SNPs). The assignment of an individual to a certain population requires prior good knowledge of the genetic structure of the species, and its reliability depends on the level of divergence between populations/stocks and the number of markers used. If the genetic distance between populations is low or/and only few genetic markers have been used, then it is difficult to assign an individual to a specific population. The advantage of a DNAbased method compared to other methods is that it can identify individuals even if they have escaped very early in their life or even if the eggs and/or gametes have escaped from net-cages into the wild and probably drifted for long distances. Differences in morphological characteristics, skeletal shape and chemical composition of the body between farmed and wild fish, can also be used to identify escapees (ArechavalaLopez et al., 2012). However, these methods are based on characteristics that are affected by the environment. If farmed individuals have escaped early in their development, they would be hardly distinguishable from the wild fish in terms of morphology but they would remain genetically distinct if farmed stocks were genetically different from the wild. The DNA stand-by method has given satisfactory results for many

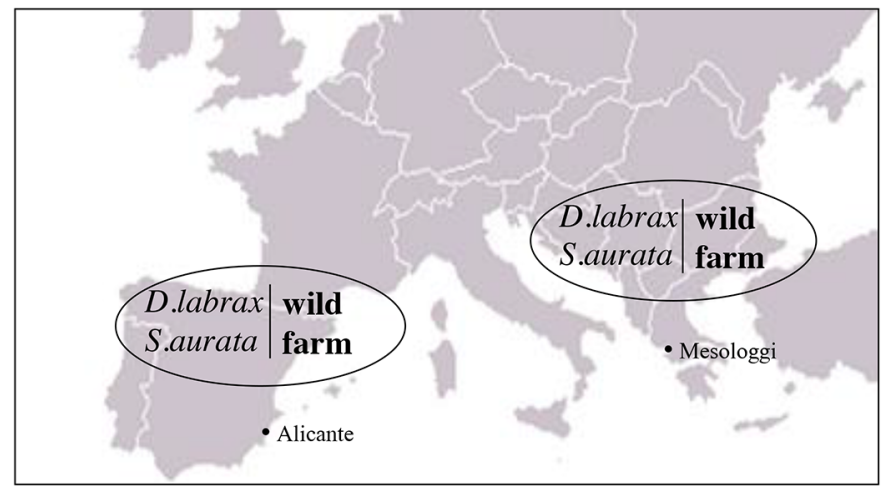

Fig 1. Geographic location of the sea bream and sea bass samples. All samples were taken from areas close to the two cities (Alicante in Spain and Mesologgi in Greece). For the exact sampling locations see Arechavala-Lopez et al. (2012b).

species such as salmon (McGinnity et al., 1997), cod (Jensen et al., 2010), sea trout (Bernas et al., 2020), rainbow trout (Glover, 2008) and red sea bream (Sawayama et al., 2019) so far but has been used to a lesser extend for gilthead sea bream and not at all for European sea bass.

The aim of this study was to investigate the genetic differences between farmed populations of seabream and seabass and their neighbouring wild populations in two countries (a fish farm from each country) and to assess the probability of identifying escapees from fish farms into the wild using DNA stand-by methods. These samples have been previously used by Arechavalla-Lopez et al. (2012), who they investigated the morphological differences between the specific populations.

\section{Materials and methods}

Farmed individuals of gilthead seabream and common seabass were sampled from a fish farm in Spain (Alicante bay) and from a fish farm in Greece (Mesologgi bay) (Fig. 1). Additionally, individuals from the wild from places that were adjacent to fish farms were sampled (Fig. 1). Each sample consisted of 100 individuals. For details of the location and the characteristics of the samples see Arechavala-Lopez et al., (2012b). From each individual, we cut a small piece of fin tissue which was stored in $90 \%$ ethanol. Total DNA was extracted from fin-clips according to the salt extraction method (Miller et al., 1988).

We used two multiplex PCR reactions to amplify 16 microsatellite loci for each species. The loci and the primers are described in Table 1. The final volume of all the reactions was $10 \mu \mathrm{l}$. Each reaction contained $1 \mu \mathrm{l}$ template DNA $(10-20 \mathrm{ng} / \mu \mathrm{l}), 1 \mu \mathrm{l}$ Taq DNA polymerase buffer $10 \times, 0.3 \mu \mathrm{l}$ from each primer (forward and reverse from a stock of $10 \mathrm{pmol} / \mu \mathrm{l}), 3 \mathrm{mM} \mathrm{MgCl} 2,0.3 \mu \mathrm{l}$ dNTPs from a stock of $10 \mathrm{mM}$ each) and $0.1 \mathrm{U}$ Taq DNA polymerase. PCR conditions were $15 \mathrm{~min}$ at $94^{\circ} \mathrm{C}$ followed by 35 cycles each of $30 \mathrm{~s}$ in $94^{\circ} \mathrm{C}, 90 \mathrm{~s}$ in $57^{\circ} \mathrm{C}\left(58^{\circ} \mathrm{C}\right.$ for D. labrax $)$ and $60 \mathrm{~s}$ in $72^{\circ} \mathrm{C}$. There was a final extension step for $10 \mathrm{~min}$ at $72^{\circ} \mathrm{C}$.

The genetic loci that we examined for $S$. aurata were 172EP, Ad-10, B13b, Bld-10, Bld-04, C67b, C77b, Cld-29, Cld-35, Ct27, Dt23, F6, F7b, Fd-92, Hd-33, P20, Saimbb25, 
Table 1. Observed and expected heterozygosity for S. aurata (A) and D. labrax (B).

\begin{tabular}{|c|c|c|c|c|c|c|c|c|c|}
\hline \multicolumn{10}{|l|}{ A. } \\
\hline Ad-10 & 0.314 & 0.266 & 0.480 & 0.450 & 0.250 & 0.221 & 0.200 & 0.182 & 3 \\
\hline $\mathrm{B} 13 \mathrm{~b}$ & 0.884 & 0.801 & 0.750 & 0.739 & 0.807 & 0.838 & 0.850 & 0.819 & 14 \\
\hline $\mathrm{C} 77 \mathrm{~b}$ & 0.547 & 0.486 & 0.50 & 0.496 & 0.598 & 0.524 & 0.463 & 0.455 & 4 \\
\hline Cld-29 & 0.733 & 0.759 & 0.720 & 0.710 & 0.667 & 0.776 & 0.675 & 0.787 & 9 \\
\hline Cld-35 & 0.651 & 0.639 & 0.430 & 0.430 & 0.727 & 0.727 & 0.738 & 0.708 & 6 \\
\hline $\mathrm{Ct} 27$ & 0.907 & 0.866 & 0.950 & 0.869 & 0.965 & 0.878 & 0.875 & 0.869 & 30 \\
\hline Dt23 & 0.907 & 0.895 & 0.900 & 0.861 & 0.909 & 0.932 & 0.863 & 0.914 & 22 \\
\hline F6 & 0.942 & 0.897 & 0.870 & 0.777 & 0.909 & 0.912 & 0.938 & 0.898 & 19 \\
\hline P20 & 0.779 & 0.777 & 0.650 & 0.645 & 0.807 & 0.786 & 0.775 & 0.740 & 13 \\
\hline Saimb25 & 0.930 & 0.859 & 0.830 & 0.809 & 0.852 & 0.866 & 0.813 & 0.881 & 12 \\
\hline SauE82 & 0.721 & 0.675 & 0.870 & 0.697 & 0.796 & 0.821 & 0.750 & 0.828 & 14 \\
\hline SauI47 & 0.643 & 0.650 & 0.697 & 0.705 & 0.580 & 0.636 & 0.705 & 0.703 & 9 \\
\hline $172 \mathrm{EP}$ & 0.535 & 0.483 & 0.520 & 0.461 & 0.534 & 0.495 & 0.625 & 0.492 & 2 \\
\hline \multicolumn{10}{|l|}{ B. } \\
\hline & \multicolumn{2}{|c|}{ FarmedSP $(N=52)$} & \multicolumn{2}{|c|}{ FarmedGR $(N=93)$} & \multicolumn{2}{|c|}{ WildSP $(N=86)$} & \multicolumn{2}{|c|}{ WildGR $(N=87)$} & No. of Alleles \\
\hline Locus & Но & $\mathrm{He}$ & Но & $\mathrm{He}$ & Но & $\mathrm{He}$ & Но & $\mathrm{He}$ & \\
\hline DLA0041 & 0.950 & 0.869 & 0.756 & 0.741 & 0.824 & 0.879 & 0.875 & 0.859 & 18 \\
\hline DLA0044 & 0.684 & 0.576 & 0.943 & 0.722 & 0.904 & 0.827 & 0.911 & 0.846 & 17 \\
\hline DLA0051 & 0.905 & 0.734 & 0.895 & 0.614 & 0.648 & 0.682 & 0.728 & 0.666 & 24 \\
\hline DLA0060 & 0.654 & 0.538 & 0.511 & 0.487 & 0.435 & 0.545 & 0.563 & 0.533 & 7 \\
\hline DLA0081 & 0.820 & 0.783 & 0.857 & 0.706 & 0.695 & 0.738 & 0.667 & 0.668 & 14 \\
\hline DLA0086 & 0.955 & 0.843 & 0.351 & 0.686 & 0.922 & 0.873 & 0.941 & 0.835 & 18 \\
\hline DLA0089 & 0.275 & 0.239 & 0.394 & 0.371 & 0.454 & 0.427 & 0.460 & 0.450 & 9 \\
\hline DLA0096 & 0.659 & 0.624 & 0.845 & 0.693 & 0.653 & 0.701 & 0.641 & 0.663 & 8 \\
\hline DLA0097 & 0.800 & 0.794 & 0.765 & 0.660 & 0.861 & 0.812 & 0.833 & 0.791 & 23 \\
\hline
\end{tabular}

SauE82, SauI47 (Franch et al., 2006; Guinand et al., 2015), whereas for D. labrax the genetic loci were DLA0041, DLA0051，DLA0044，DLA0060，DLA0061， DLA0064, DLA0066, DLA0068, DLA0073, DLA0075, DLA0078, DLA0081, DLA0086, DLA0089, DLA0096, DLA0097, (Chistiakov et al., 2008; Guinand et al., 2015). These are commonly used microsatellite polymorphic loci in both species.

PCR products were run on an ABI PRISMs 3700 DNA Analyzer (Applied Biosystems, Carlsbad, CA, USA), using 5'-labelled reverse primers and the GeneScanTM- 500 LIZs Size Standard (Applied Biosystems) as an internal size standard for allele sizing. Alleles were sized using the software STRAND 2.3.79 (http://www.vgl.ucdavis.edu/informatics/STRand/).

\section{Statistical analysis}

Adegenet R package (Jombart and Ahmed, 2011) was employed to calculate observed and expected heterozygosites, and GENETIX 4.05 (Belkhir et al., 2000) for gene diversity and number of alleles. Detection of loci with excess in null alleles, F statistics, departure from Hardy-Weinberg Equilibrium (HWE) as well as linkage analysis between loci were performed with GENEPOP 3.4 (Raymond and Rousset, 1995). Adegenet (Jombart and Ahmed, 2011) was used to perform a discriminate analysis of principal components (DAPC). The analysis produced the same results independently of the number of axes that we retain in the principal component analysis step or in the discriminant analysis. Finally, we performed a Bayesian clustering analysis using STRUCTURE 
2.3 (Pritchard et al., 2000; Falush et al., 2003), assuming a number of $K$ populations (maximum value set $K=7$ ), using the default settings with twenty independent runs for each $K$, $1,000,000$ iterations and a burn-in period of 100,000 . Then we used the Harvest online software (Earl and Vonholdt, 2012) which uses the Evanno's algorithm (Evanno et al., 2005), to find the best $K$ value. Given that we would like to identify escapees from the fish farms, we also run Structure for Greek farmed and wild samples as well as for Spanish farmed and wild samples, using $K=2$ as a default value. We visualize the STRUCTURE results with the program STRUCTURE PLOT v.2 (Ramasamy et al., 2014). We have run the software multiple times with membership coefficient ranging from $70 \%$ to $80 \%$; results did not change qualitatively (data not shown) and the $75 \%$ was finally used as a threshold for the analysis of current data. Therefore, an individual belongs to a certain group if the membership coefficient is higher than $75 \%$; otherwise, that individual is assigned as belonging to the alternative group.

\section{Results}

\subsection{Genetic population structure}

\subsubsection{Sparus aurata}

We genotyped 19 loci for $S$. aurata but we excluded locus C67b from the analysis as having significant excess of null alleles in all four samples; thus, 18 loci were finally retained. We detected 262 different alleles in all samples of $S$. aurata (Tab. 1A). The number of alleles per locus varied from 2 (locus 172EP) to 30 (locus Ct27). We also detected 45 private alleles (alleles appeared only in a single sample), which represent $17 \%$ of the total number of alleles. Seven and 15 of the private alleles were found in wild and farmed Greek samples, respectively, and two and 21 were found in Spanish wild and farmed samples, respectively. Private alleles were equally distributed across populations (Kruskal-Wallis, $p=0.1322$ ). Gene diversity was highly variable across loci (Tab. 1A), and ranged from 0.086 in locus Blt-10 in Greek farmed sample to 0.932 in locus Dt23 in the wild Spanish sample. Nevertheless, different samples had not significantly different gene diversities (Kruscal-Wallis, $p=0.4451$ ).

All four samples appear to be in Hardy Weinberg disequilibrium $(p=0.000)$. Three loci in Spanish farmed sample, eight loci in Greek farmed sample, two loci in Spanish wild sample and two loci in Greek wild sample were significantly departed from HWE. In eight of 18 loci that showed significant departure from HWE, $F_{\mathrm{IS}}$ was greater than zero indicating inbreeding. In some cases, $F_{\text {IS }}$ was high (e.g. 0.101 in locus SauE82 for the Greek wild samples (Tab. 2A). In cases that $F_{\text {IS }}$ was significantly lower than zero, its values were close to zero except from the Greek farmed population that $F_{\text {IS }}$ was -0.244 , $-0.209,-0.115$ and -0.114 in four loci.

The four samples were distinct from each other, as the $F_{\mathrm{ST}}$ index is significantly different from zero between all pairs of samples except for the wild Spanish and Greek samples (Tab. 3A). This is confirmed by Nei distance, which shows that the closest samples were the wild Spanish and Greek ones. The more distantly related samples were the farmed Spanish and the farmed Greek $\left(F_{\mathrm{ST}}=0.0778\right.$, Nei distance $\left.=0.2020\right)$.
The DAPC analysis showed a similar picture; wild Spanish and wild Greek samples could not be distinguished from each other, whereas both the farmed Greek and Spanish samples formed distinct groups (Fig 2A).

\subsubsection{Dicentrarchus labrax}

All the 16 loci that we used for D. labrax were polymorphic with a total number of 243 alleles in all samples, and mean number of alleles greater than 15 (Tab. 1B). The total number of alleles per locus varied from 6 alleles in the locus DLZ-377 to 24 alleles in locus DLA0051. We identified 48 private alleles, which correspond to $28 \%$ of the total number of alleles. Private alleles are not equally distributed across samples (Kruskal-Wallis test, $p=0.000122$ ).

The expected heterozygosity ranged from 0.239 (locus DLA0089, in farmed Spanish sample) to 0.915 (in locus DLA0073, in wild Spanish sample) (Tab. 1B). The differences in gene diversity among samples were not significant (KruskalWallis test, $p=0.51$ ).

All four samples were not in Hardy-Weinberg equilibrium ( $p=0.000$ for each of the populations). However, not all individual loci were significantly departed from HardyWeinberg equilibrium as shown in $F_{\text {IS }}$, the inbreeding coefficient, which was significantly different from zero only in few loci for each population (in 6 and 5 loci in farmed and wild samples from Spain and in 10 and one loci in farmed and wild Greek samples, respectively) (Tab. 2B). When $F_{\text {IS }}$ was significantly different from zero, it was negative in most of the cases (in 13 out of 22). Interestingly, the farmed Greek sample had 10 loci departed from HWE, and in eight of them the $F_{\text {IS }}$ was negative. On the other hand, in this population $F_{\text {IS }}$ had the highest positive $F_{\text {IS }}$ value $(0.493)$.

All samples were significantly differentiated from each other as indicated by the $F_{\mathrm{ST}}$ index (Tab. 3B). The higher differentiation was between the farmed Greek and the farmed Spanish samples according to $F_{\mathrm{ST}}\left(F_{\mathrm{ST}}=0.199\right)$, whereas according to Nei distance the higher differentiation was between the wild Spanish sample and the farmed Greek sample (Nei distance $=0.697)$. However, the distance between this pair of samples and farmed Greek and Spanish samples was very similar $($ Nei distance $=0.679)$. The lowest differentiation was between the wild and farmed samples from $\operatorname{Spain}\left(F_{\mathrm{ST}}=0.038\right.$, Nei distance $=0.123$ ). DAPC analysis produced similar results (Fig 2B); farmed and wild Spanish samples formed an indiscriminate group, whereas farmed and wild Greek samples formed two highly distinct groups.

\subsection{Genetic assignment}

\subsubsection{S. aurata}

We run STRUCTURE until convergence and the Bayesian analysis revealed that all four populations of S. aurata could be assigned into two clusters as indicated by Evanno's test $(\Delta K=172.7955)$. In the next alternative $(K=3)$, the $\Delta K$ was 74.3202. This clustering is different from the DAPC analysis in which both Spanish samples and the Greek wild sample formed a single group, whereas the Greek farmed samples formed a different cluster (Fig. 3A). 
Table 2. $F_{\text {IS }}$ for $S$. aurata $(\mathrm{A})$ and D. labrax (B)

\begin{tabular}{|c|c|c|c|c|c|c|c|c|}
\hline \multicolumn{9}{|l|}{ A. } \\
\hline \multirow[b]{2}{*}{ locus } & \multicolumn{2}{|c|}{ Farmed SP } & \multicolumn{2}{|c|}{ Farmed GR } & \multicolumn{2}{|c|}{ Wild SP } & \multicolumn{2}{|c|}{ Wild GR } \\
\hline & FIS & $p$-value & FIS & $p$-value & FIS & $p$-value & FIS & $p$-value \\
\hline $172 \mathrm{EP}$ & -0.102 & 0.378 & -0.124 & 0.278 & -0.074 & 0.526 & -0.264 & 0.021 \\
\hline Ad-10 & -0.173 & 0.316 & -0.062 & 0.002 & -0.124 & 0.693 & -0.092 & 1.000 \\
\hline Bld-10 & 0.017 & 0.075 & -0.037 & 1.000 & 0.068 & 0.255 & 0.014 & 0.146 \\
\hline $\mathrm{C} 77 \mathrm{~b}$ & -0.118 & 0.379 & -0.003 & 0.733 & -0.135 & 0.161 & -0.011 & 1.000 \\
\hline Cld-29 & 0.040 & 0.619 & -0.009 & 0.620 & 0.146 & 0.454 & 0.148 & 0.065 \\
\hline Cld-35 & -0.013 & 0.563 & 0.006 & 0.867 & 0.005 & 0.231 & -0.036 & 0.117 \\
\hline $\mathrm{Ct} 27$ & -0.042 & 0.058 & -0.089 & 0.013 & -0.093 & 0.088 & -0.001 & 0.420 \\
\hline Fd-92 & 0.119 & 0.265 & -0.118 & 0.208 & 0.169 & 0.000 & 0.157 & 0.008 \\
\hline P20 & 0.003 & 0.811 & -0.003 & 0.707 & -0.021 & 0.922 & -0.041 & 0.760 \\
\hline B13b & -0.097 & 0.366 & 0.010 & 0.008 & 0.043 & 0.605 & -0.032 & 0.469 \\
\hline Bld-04 & 0.020 & 0.039 & -0.092 & 0.007 & 0.082 & 0.535 & 0.074 & 0.796 \\
\hline Dt23 & -0.008 & 0.042 & -0.040 & 0.176 & 0.030 & 0.174 & 0.062 & 0.081 \\
\hline F6 & -0.045 & 0.246 & -0.115 & 0.000 & 0.009 & 0.064 & -0.038 & 0.986 \\
\hline $\mathrm{F} 7 \mathrm{~b}$ & 0.048 & 0.048 & -0.114 & 0.000 & 0.090 & 0.444 & 0.082 & 0.157 \\
\hline Hd-33 & -0.033 & 0.796 & -0.209 & 0.013 & 0.065 & 0.034 & -0.042 & 0.921 \\
\hline Saimbb25 & -0.077 & 0.230 & -0.022 & 0.766 & 0.021 & 0.374 & 0.084 & 0.144 \\
\hline SauE82 & -0.063 & 0.936 & -0.244 & 0.010 & 0.037 & 0.749 & 0.101 & 0.017 \\
\hline SauI47 & 0.017 & 0.933 & 0.017 & 0.055 & 0.094 & 0.790 & 0.003 & 0.260 \\
\hline \multicolumn{9}{|l|}{ B. } \\
\hline & \multicolumn{2}{|c|}{ Farmed SP } & \multicolumn{2}{|c|}{ Farmed GR } & \multicolumn{2}{|c|}{ Wild SP } & \multicolumn{2}{|c|}{ Wild GR } \\
\hline Locus & $F_{\text {IS }}$ & $p$-value & $F_{\text {IS }}$ & $p$-value & $F_{\text {IS }}$ & $p$-value & $F_{\text {IS }}$ & $p$-value \\
\hline DLA0041 & -0.080 & 0.002 & -0.015 & 0.332 & 0.069 & 0.170 & -0.013 & 0.793 \\
\hline DLA0044 & -0.175 & 0.593 & -0.301 & 0.000 & -0.086 & 0.658 & -0.070 & 0.710 \\
\hline DLA0051 & -0.221 & 0.980 & -0.453 & 0.000 & 0.057 & 0.182 & -0.087 & 0.168 \\
\hline DLA0060 & -0.207 & 0.349 & -0.044 & 0.278 & 0.207 & 0.204 & -0.051 & 0.269 \\
\hline DLA0061 & -0.201 & 0.371 & -0.359 & 0.000 & -0.110 & 0.340 & -0.007 & 0.777 \\
\hline DLA0064 & -0.092 & 0.159 & 0.117 & 0.000 & 0.088 & 0.015 & -0.032 & 0.932 \\
\hline DLA0066 & -0.063 & 0.093 & 0.049 & 0.475 & 0.008 & 0.003 & 0.078 & 0.401 \\
\hline DLA0068 & -0.094 & 0.550 & -0.239 & 0.104 & -0.095 & 0.117 & -0.011 & 1.000 \\
\hline DLA0073 & 0.071 & 0.024 & -0.163 & 0.014 & 0.028 & 0.012 & -0.035 & 0.997 \\
\hline DLA0075 & -0.154 & 0.330 & -0.123 & 0.039 & 0.009 & 0.023 & 0.126 & 0.193 \\
\hline DLA0078 & -0.087 & 0.002 & -0.313 & 0.000 & -0.016 & 0.252 & 0.033 & 0.373 \\
\hline DLA0081 & -0.037 & 0.000 & -0.207 & 0.086 & 0.064 & 0.218 & 0.009 & 0.392 \\
\hline DLA0086 & -0.121 & 0.023 & 0.493 & 0.000 & -0.049 & 0.006 & -0.121 & 0.349 \\
\hline DLA0089 & -0.137 & 0.638 & -0.054 & 0.560 & -0.057 & 1.000 & -0.015 & 0.857 \\
\hline DLA0096 & -0.044 & 0.056 & -0.212 & 0.000 & 0.076 & 0.088 & 0.040 & 0.040 \\
\hline DLA0097 & 0.005 & 0.034 & -0.152 & 0.050 & -0.053 & 0.208 & -0.047 & 0.512 \\
\hline
\end{tabular}

Table 3. Pairwise $F_{\mathrm{ST}}$ (below diagonal) and Nei distance (above diagonal) values among samples of $S$. aurata (A) and D. labrax (B).

\begin{tabular}{|c|c|c|c|c|c|c|c|c|}
\hline \multicolumn{5}{|c|}{ A } & \multicolumn{4}{|c|}{ B } \\
\hline Farmed SP & & 0.078 & 0.018 & 0.021 & & 0.199 & 0.038 & 0.166 \\
\hline Farmed GR & 0.202 & & 0.065 & 0.068 & 0.679 & & 0.179 & 0.122 \\
\hline Wild GR & 0.067 & 0.176 & 0.014 & & 0.685 & 0.36 & 0.601 & \\
\hline
\end{tabular}

We then run separately the Spanish (Fig. 3B) and the Greek samples (Fig. 3C), inferring two clusters in each location, which corresponded to farmed and wild samples. This correspondence was poor for Spanish samples but stronger for Greek samples. The proportion of membership for Spanish farmed samples to belong to one cluster was 0.618 and for Spanish wild samples to belong to the second cluster was 0.892 . For the Greek samples, the proportion of membership to one cluster for the farmed samples was 0.926 and for the wild samples the proportion of membership to the second cluster 
A

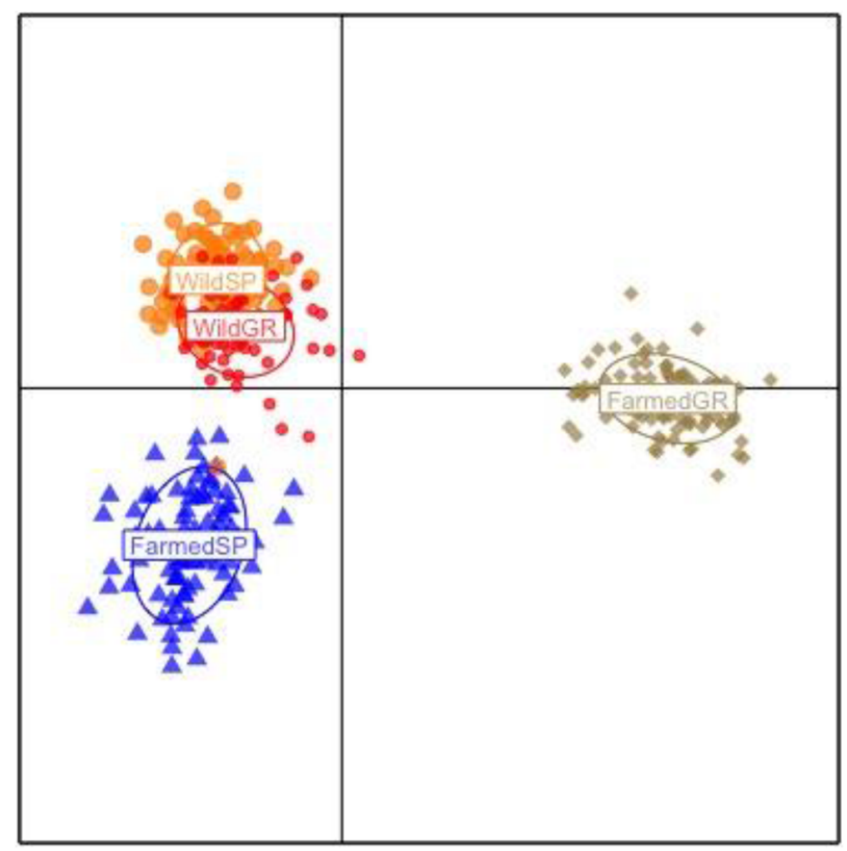

B.

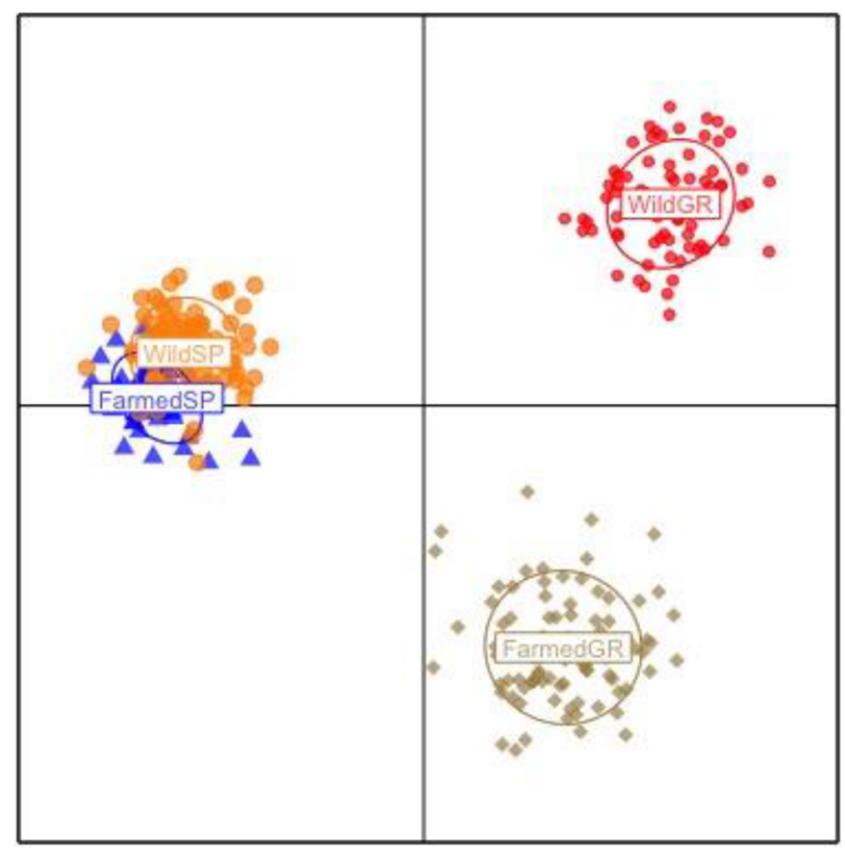

Fig. 2. Discriminate analysis of principal components (DAPC) A. $S$. aurata B. D labrax. Different colors represent different samples.

was 0.965 indicating strong grouping. When we considered the probability of participating to one or the other cluster for each individual separately, 27 individuals from Spanish farmed population failed to participate in any of the two clusters (probability of participation less than 0.75), 42 individuals belonged to one cluster and 17 to the other. Thus, the origin of the farmed Spanish sea-bream sample seems to be obscure. On the other hand, the wild population seems to be genetically more concrete. Only ten out of 88 individuals failed to be assigned to a cluster, with probability higher than 0.75 and the rest 77 formed a distinct cluster. From these results, we do not have clear evidence for escapees from the farmed samples to the wild. However, given that the Spanish farmed samples do not form a concrete group, the genetic characterization of escapees is not possible.

For the Greek farmed sample, 11 individuals failed to be assigned to a single cluster. Eighty-eight individuals formed a well-defined cluster and one individual belonged to the alternative cluster. For the Greek wild sample, 79 individuals belonged to a single cluster (different from that of the farmed samples) and one individual failed to be assigned to a cluster. Thus we have no evidence for escapees from the farm to the wild in this sample.

\subsubsection{D. labrax}

We run together all four samples of D. labrax for Bayesian clustering. The Evanno's algorithm suggested three groups (Evanno et al., 2005) $(\Delta K=219.7664)$ (Fig. 4A). The farmed and wild Greek samples formed two distinct groups, whereas the Spanish samples formed a single group. This is consistent with the DPAC Analysis (Fig. 3B).

Given that we would like to test whether there were escapees from the farmed to wild populations we run STRUCTURE separately for the Spanish (Fig. 4B) and the Greek samples (Fig. 4C) defining $K=2$ for farmed and wild samples in each location. The proportion of membership to the farmed and wild groups for Greek individuals was on average 0.937 and 0.985 , respectively. Similarly, for the Spanish samples the proportion of participation to farmed and wild samples was on average 0.875 and 0.855 , respectively. There were two individuals from the Spanish farmed samples that showed probability of participation to the wild group higher than 0.75 (probabilities 0.810 and 0.806 ). There were also two individuals from the wild sample that appeared to come from the farmed population. One of these individuals had probability of participation to the farmed sample 0.821 and the other 0.977 . These two individuals are potentially escapees.

There were five (out of 52) individuals from the Spanish farmed sample and 12 (out of 86) individuals from wild Spanish sample, as well as five (out of 93) individuals from Greek farmed sample and none (out of 87) individuals from Greek wild sample that could not be assigned to one or the other group, i.e. the probability of participation to any group was lower than 0.75 .

\section{Discussion}

\subsection{Wild populations}

Large-scale genetic studies suggest that wild populations of D. labrax are clustered into three large genetic pools: the Atlantic, which is separated from western Mediterranean in the Almeria-Oran front, the western Mediterranean and the eastern Mediterranean. Some studies show low but significant $F_{\mathrm{ST}}$ values between local populations (Naciri et al., 1999; Lemaire et al., 2000; Tine et al., 2014; Souche et al., 2015; Vandeputte et al., 2019). Even though our samples are not representative of the variation in all populations from the two countries, our 
A.

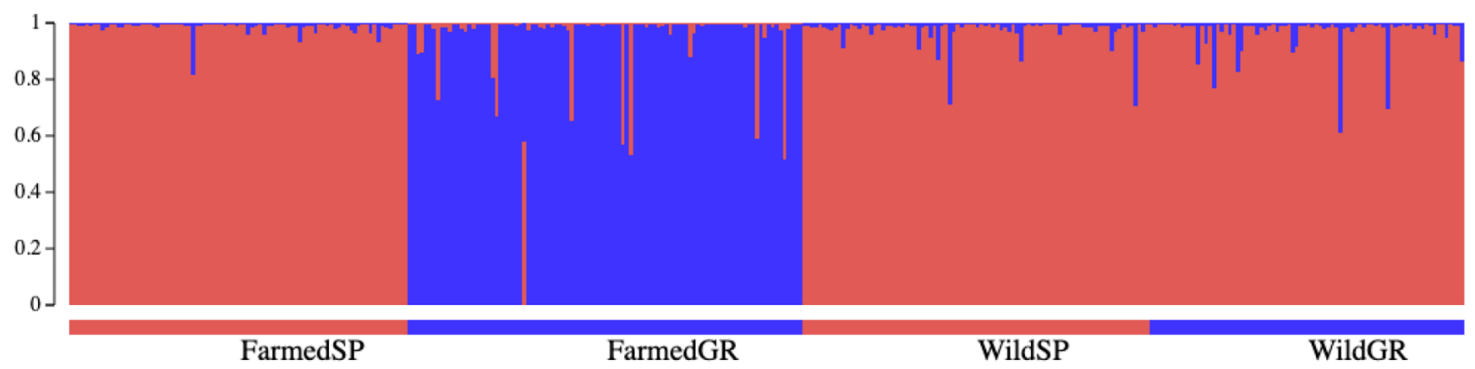

B.

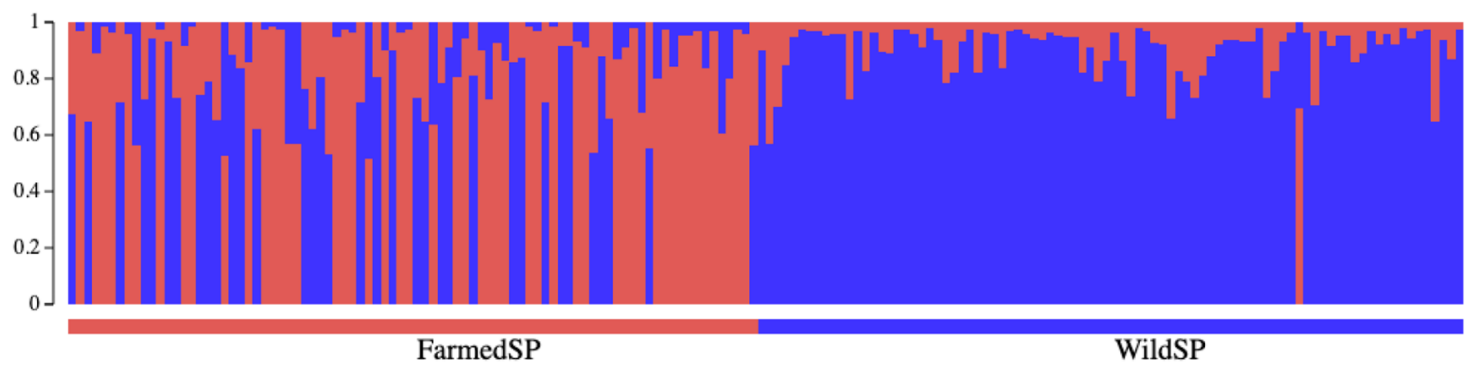

C.

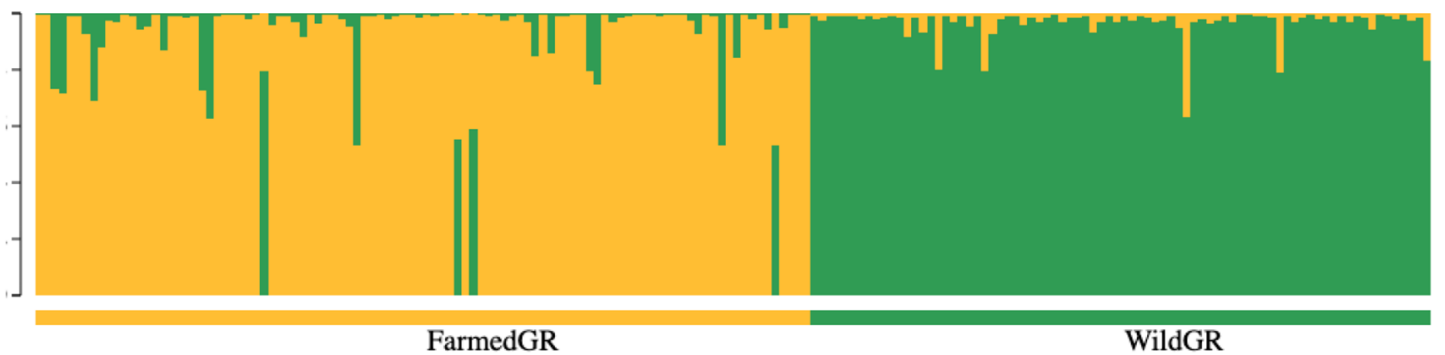

Fig. 3. Bayesian clustering of $S$. aurata samples. A. All four samples form two clusters. B. Spanish samples. C. Greek samples. The different colors represent the groups that the program STRUCTURE has clustered the individuals. The length of the colored bar shows the probability that a specific individual belongs to the respective group. The length of the colored bars per individual adds up to 1 .

results confirm that the wild Greek and Spanish seabass samples are distinct with significant $F_{\mathrm{ST}}$ value.

Most of the previous studies suggest that seabass wild populations in the three genetic pools are in Hardy-Weinberg equilibrium if some loci were excluded (Garcia DeLeon et al., 1997; Naciri et al., 1999; Lemaire et al., 2000; Lemaire et al., 2005). Other studies using a different set of markers, show that local wild populations are in Hardy-Weinberg disequilibrium (Castilho and Ciftci, 2005). This difference between studies could be probably due to genetic markers used in each study.

Population genetics of $S$. aurata show a different pattern than D. labrax. Low but significant $F_{\mathrm{ST}}$ values indicate that seabream has genetically distinct local populations rather than large genetic (Ben Slimen et al., 2004; Rossi et al., 2006; Gkagkavouzis et al., 2019). Through the Aquatrace project (https://cordis.europa.eu/project/rcn/105481/reporting/en), clustering analysis suggested a relatively strong subdivision between Atlantic and Mediterranean basins ( $F_{\mathrm{ST}}$ values $2 \%-3 \%$ ) and a less strong, though significant subdivision within the Mediterranean in three "sub-basins" (West Mediterranean, Ionian and Aegean) $\left(F_{\mathrm{ST}}\right.$ values from 0 to $\left.1.8 \%\right)$ in sea bream wild populations. In this context, Gkagkavouzis et al. (2019) analyzed wild sea bream populations around Greece and they report that the populations appeared to be highly admixed and no geographic clusters are evident in structure plots. Our results confirm the differentiation between wild Greek and Spanish Mediterranean populations as well as the departure from HWE.

Natural populations could depart from HWE for several reasons such as inbreeding, admixture of previously separated populations, thus increase of heterozygosity (Wahlund effect), selection or presence of null alleles that artificially increases homozygosity. In our populations, selection could be excluded because it would seem highly unlikely a large number of random microsatellite loci to be under selection. The effect of null alleles can also be excluded because in our analysis we have tested for excess of null alleles. The negative $F_{\text {IS }}$ values indicate that departure from HWE in our study us most possibly is explained by the admixture of previously separated populations. 
A.

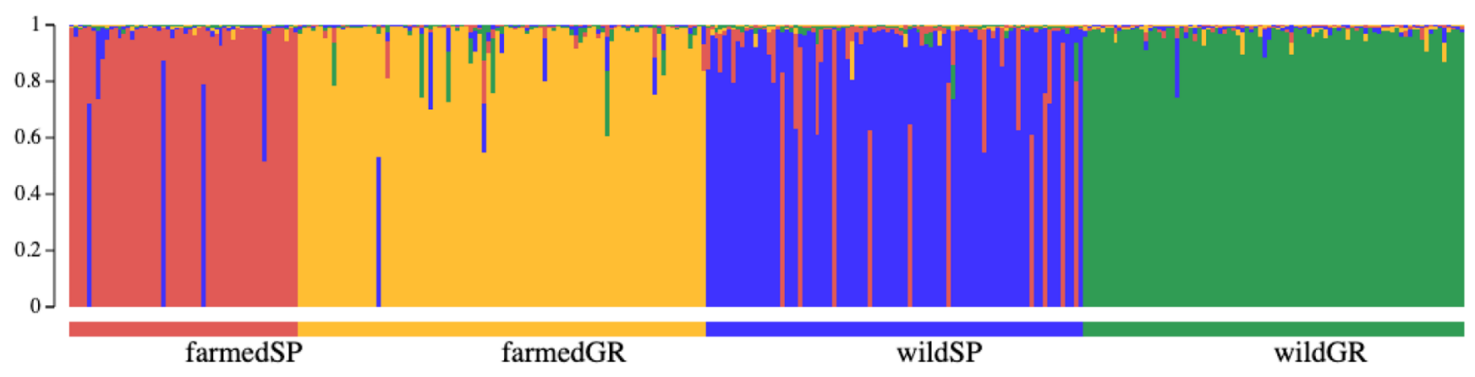

B.

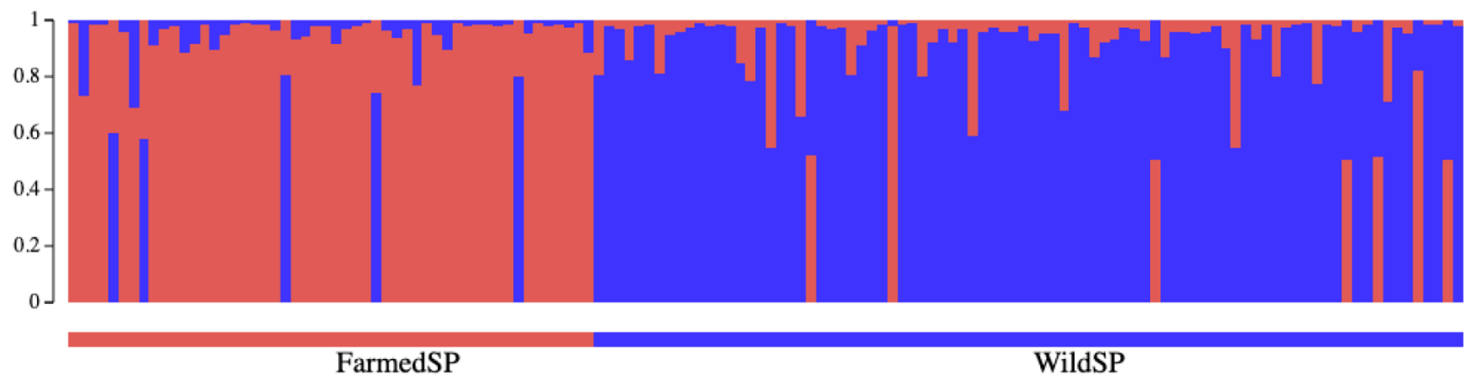

C.

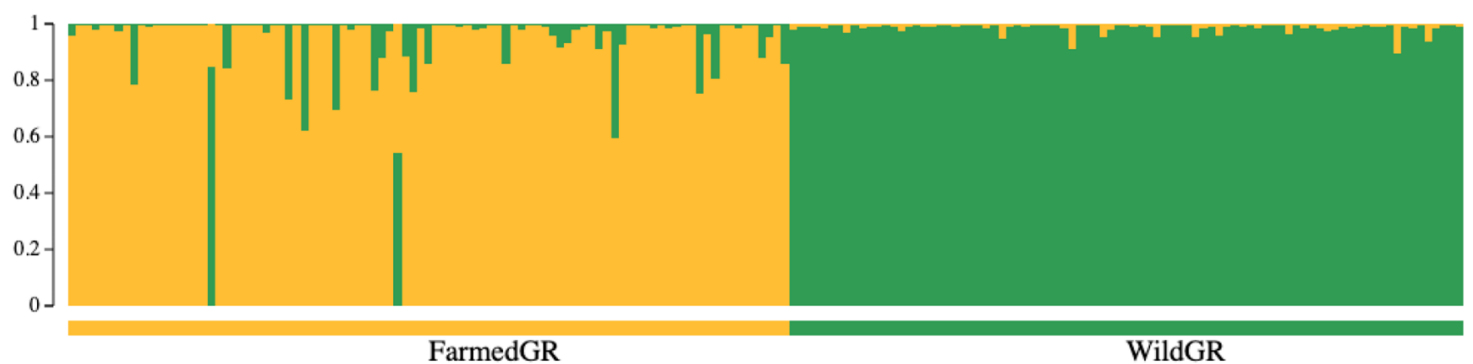

Fig. 4. Bayesian clustering of D. labrax samples. A. All four samples. B. Spanish samples. C. Greek samples. The different colors represent the groups that the program STRUCTURE has clustered the individuals. The length of the colored bar shows the probability that a specific individual belongs to the respective group. The length of the colored bars per individual adds up to 1.

\subsection{Farmed populations}

The Greek farmed samples that we examined were significantly different from the wild samples both for gilthead seabream and for European seabass. This was obvious both from the $F_{\mathrm{ST}}$ and from the Bayesian analyses. For the Spanish farmed samples, even though $F_{\mathrm{ST}}$ showed low but significant differentiation, Bayesian analysis grouped the two samples into a single cluster both for seabream and for seabass. Previous studies have compared wild and farmed Greek populations of $S$. aurata and revealed that the farmed populations were distinct from the wild ones (Alarcon et al., 2004; Karaiskou et al., 2009; Loukovitis et al., 2011). Interestingly, Karaiskou et al. (2009) found that among distantly related wild Greek seabream populations there was no genetic differentiation, while farmed fish from different cages of the same fish farm formed genetically distinct groups. Likewise, Loukovitis et al. (2011) using microsatellites and Alarcon et al. (2004) using both microsatellites and allozymes showed significant genetic differentiation of farmed sea bream from their proximal wild populations in different sites across north Mediterranean. Last, in the Aquatrace project, the report cites that the farm broodstocks are generally less genetically diverse than wild populations, and additionally broodstocks are more differentiated among each other $\left(F_{\mathrm{ST}}\right.$ ranging between $1.2 \%$ and $5.7 \%$ ), which might be the results of strong genetic drift for many generations of selection or founder effects. However, when these broodstocks are compared to the wild counterpart, most of them are markedly different from them with the exception of broodstocks with a more recent history of hatchery selection which display similarities with some wild populations.

To our knowledge, there are limited previous studies for seabass to compare the genetic structure of farmed and wild populations. In such a study they found that the two of three aquaculture stocks were outbred (Bahri-Sfar et al., 2005). The results for gilthead seabream corroborate our findings, which suggest that at least the Greek farmed sample was significantly 
distinct from the wild populations. Greek farmed sample was highly differentiated from all the other populations particularly for seabass. $F_{\mathrm{ST}}$ values are high and $F_{\mathrm{IS}}$ values are small. There are three potential scenarios to explain the genetic differentiation between farmed and wild samples in Greece but not in Spain. First, farmed samples might have different geographic origin from the proximal wild samples. Second, farmed sample might have been originated from local populations but they carry a small proportion of the genetic diversity of wild populations. Finally, farmed sample might have been originated from selective breeding programs, where artificial selection might have changed the genetic structure of the selected population.

From these potential explanations we can exclude the sampling effect because if farmed sample was a subsample of the adjacent wild populations, it should not contain private alleles, given that sample size for both farmed and wild samples is high enough. Selection alone would also have fewer odds to explain the results, because selective breeding has been very recently applied in both species. Nevertheless, it would seem unlikely that an artificial selection program could change the genetic structure of a species for neutral loci in few generations. The most plausible explanation would be that the fingerlings come from a different geographic region. A combination of different scenarios also cannot be excluded. For example, fingerlings might have been imported from a different country and be part of a selective breeding program.

The Messolonghi-Etoliko lagoon complex in Western Greece coast (Ionian Sea) is composed of six lagoons and represents one of the most important coastal lagoon systems in the Mediterranean Sea (Dimitriou et al., 2007). More than 25\% of Greek fish farms and $20 \%$ of Greek hatcheries of gilthead sea bream and sea bass are located in this lagoon system (source: Mariculture Federation of Greece). It is known that for both species, strains of foreign origin are bought and raised in fish farms because they are considered to grow faster. Furthermore, during the last decade, a spectacular increase in the number of farms and their production, accompanied by a substantial price decrease resulted in the maintenance in cages of large individuals (more than $500 \mathrm{~g}$ ) of gilthead seabream, which are potential spawners. Extensive histological investigation of gonads sampled from different farms in the two major regions for aquaculture activities in Greece revealed that female sea bream cultivated beyond the size of sex reversal matured, ovulated and released eggs during the normal spawning period of the species; moreover, the genetic identification of sparid eggs demonstrated that sea bream eggs were spawned in farms and released to the environment (Somarakis et al., 2013). Escapees from cages have a rather accidental character and fluctuate from year to year due to invasion of large pelagic species or adverse weather conditions. Considering that only farms covered by a specific insurance provide these data, it is clear that the number of escaped individuals was even greater (Dimitriou et al., 2007).

Are the populations different enough to allow us correctly allocating each individual to a certain population? Bayesian analysis suggests that Greek but not Spanish farmed and wild samples are distinct well enough, and such allocation is possible with high probability. This is particularly interesting to find the escaped fish. The genetic method for allocation of escapees has been successfully used for tracing escapee salmon, rainbow trout and Atlantic cod back to their farm of origin (Glover, 2010). It seems a promising method, which has not been validated either for sea bream or for sea bass (but see Segvic-Bubic et al., 2011). Our results are encouraging, at least for the Greek populations. The common practice to move seed from a geographic location to other for farming as well as the recent programs for selective breeding of these species increase the probability of identifying genetically the escaped fish but increases the danger for the escapees to "genetically contaminate" the local populations. In certain cases, like in the Messolonghi-Etoliko lagoon which is a typical nursery for the species, the unintentional escapes in the natural environment may have devastating consequences, since alleles or genes of "alien" origin could be imported and propagate faster in the wild gene pool.

Arechavala-Lopez et al. (2012a) recommended the use of molecular genetic markers as a suitable tool for genetic discrimination of wild and farmed fish, enabling monitoring of the genetic impact of fish farm escapes and/or restocking releases. Broodstocks and their offspring could be genotyped in hatcheries before going to open-sea cages, and such information should be available to the scientific community and managers, in order to improve the accuracy and suitability of genetic tools.

Acknowledgments. This study was financed by the European Union 7th Research Framework Project "Prevent Escape" (no. 226885; www.preventescape.eu). We thank Vasso Terzoglou and Katerina Ekonomaki for lab assistance

\section{References}

Alarcon JA, Magoulas A, et al. 2004. Genetic comparison of wild and cultivated European populations of the gilthead sea bream (Sparus aurata). Aquaculture 230: 65-80.

Arechavala-Lopez P, Fernandez-Jover D, et al. 2012a. Differentiating the wild or farmed origin of Mediterranean fish: a review of tools for sea bream and sea bass. Rev Aquacult 4: 1-21.

Arechavala-Lopez P, Sanchez-Jerez P, et al. 2012b Morphological differences between wild and farmed Mediterranean fish. Hydrobiologia 679: 217-231.

Arechavala-Lopez P, Toledo-Guedes K, et al. 2018. Implications of sea bream and sea bass escapes for sustainable aquaculture management: a review of interactions, risks and consequences. Rev Fish Sci Aquac 26: 214-234.

Barazi-Yeroulanos L. Regional synthesis of the Mediterranean marine finfish aquaculture sector and development of a strategy for marketing and promotion of Mediterranean aquaculture (MedAqua- Market). Studies and Reviews General Fisheries Commission for the Mediterranean $\mathrm{N}^{\circ}$ 88. Food and Agriculture Organization, Rome, Italy, 2010.

Barth JMI, Berg PR, et al. 2017. Genome architecture enables local adaptation of Atlantic cod despite high connectivity. Mol Ecol 26 : 4452-4466.

Belkhir K, Borsa P, et al. 2000. Genetix version 4.02. logiciel sous Windows ${ }^{\mathrm{TM}}$ pour la génétique des populations. Montpellier.

Ben Slimen H, Guerbej H, et al. 2004. Genetic differentiation between populations of gilthead seabream (Sparus aurata) along the Tunisian coast. Cybium 28: 45-50. 
Bernas R, Pocwierz-Kotus A, et al. 2020. Genetic differentiation in hatchery and stocked populations of sea trout in the Southern Baltic: selection evidence at SNP loci. Genes (Basel) 11.

Castilho R, Ciftci Y. 2005. Genetic differentiation between close eastern Mediterranean Dicentrarchus labrax (L.) populations. $J$ Fish Biol 67: 1746-1752.

Chistiakov DA, Tsigenopoulos CS, et al. 2008. A combined AFLP and microsatellite linkage map and pilot comparative genomic analysis of European sea bass Dicentrarchus labrax L. Animal Genet 39: 623-634.

D'Ambrosio J, Phocas F, et al. 2019. Genome-wide estimates of genetic diversity, inbreeding and effective size of experimental and commercial rainbow trout lines undergoing selective breeding. Genet Sel Evol 51: 26.

de Oliveira RC, Santos MdCoF, et al., 2018, From river to farm: an evaluation of genetic diversity in wild and aquaculture stocks of Brycon amazonicus (Spix \& Agassiz, 1829), Characidae, Bryconinae. Hydrobiologia 805, 75-88.

Dempster T, Moe H, et al. 2007. Escapes of marine fish from sea-cage aquaculture in the Mediterranean Sea: status and prevention. CIESM Workshop Monogr 32: 55-60.

Dimitriou E, Katselis G, et al. 2007. Possible influence of reared gilthead sea bream (Sparus aurata, L.) on wild stocks in the area of the Messolonghi lagoon (Ionian Sea, Greece). Aquacult Res 38: 398-408.

Earl DA, Vonholdt BM. 2012. Structure Harvester: a website and program for visualizing Structure output and implementing the Evanno method. Conserv Genet Resour 4: 359-361.

Evanno G, Regnaut S, et al. 2005. Detecting the number of clusters of individuals using the software Structure: a simulation study. Mol Ecol 14: 2611-2620.

Falush D, Stephens M, et al. 2003. Inference of population structure using multilocus genotype data: linked loci and correlated allele frequencies. Genetics 164: 1567-1587.

Fleming IA, Hindar K, et al. 2000. Lifetime success and interactions of farm salmon invading a native population. $P$ Roy Soc Lond B Bio 267: 1517-1523.

Franch R, Louro B, et al. 2006. A genetic linkage map of the hermaphrodite teleost fish Sparus aurata L. Genetics 174: 851-861.

Garcia DeLeon FJ, Chikhi L, et al. 1997. Microsatellite polymorphism and population subdivision in natural populations of European sea bass Dicentrarchus labrax (Linnaeus, 1758). Mol Ecol 6: 51-62.

Gkagkavouzis K, Karaiskou N, et al. 2019. The genetic population structure and temporal genetic stability of gilthead sea bream Sparus aurata populations in the Aegean and Ionian Seas, using microsatellite DNA markers. J Fish Biol 94: 606-613.

Glover KA. 2008. Genetic characterisation of farmed rainbow trout in Norway: intra- and inter-strain variation reveals potential for identification of escapees. BMC Genet 9, 87 .

Glover KA. 2010. Forensic identification of fish farm escapees: the Norwegian experience. Aquacult Env Interac 1: 1-10.

Guinand B, Quere N, et al. 2015. From the laboratory to the wild: salinity-based genetic differentiation of the European sea bass (Dicentrarchus labrax) using gene-associated and gene-independent microsatellite markers. Mar Biol 162(3): 515-538. Mar Ecol Prog Ser 558: 115-127.

ICES. Report of the Working Group on Environmental Interactions of Mariculture (WGEIM). Narragansett, Rhode Island, USA, p. 195, 2006.

ICES. Report of the Working Group on Aquaculture (WGAQUA). Narragansett, USA, ICES (WGQUA), p. 151, 2015.
Jensen Ò, Dempster T, et al. 2010. Escapes of fishes from Norwegian sea-cage aquaculture: causes, consequences and prevention. Aquacult Env Interac 1, 71-83.

Jombart T, Ahmed I. 2011, Adegenet 1.3-1: new tools for the analysis of genome-wide SNP data. Bioinformatics 27: 3070-3071.

Karaiskou N, Triantafyllidis A, et al. 2009 Microsatellite variability of wild and farmed populations of Sparus aurata. J Fish Biol 74, 1816-1825.

Lemaire C, Allegrucci G, et al. 2000. Do discrepancies between microsatellite and allozyme variation reveal differential selection between sea and lagoon in the sea bass (Dicentrarchus labrax)? Mol Ecol 9: 457-467.

Lemaire C, Versini JJ, et al. 2005. Maintenance of genetic differentiation across a transition zone in the sea: discordance between nuclear and cytoplasmic markers. $J$ Evol Biol 18, 70-80.

Lilia BS, Christophe L, Béatrice C, Pascal D, Oum KBH, François B, 2005. Impact of aquaculture on the genetic structure of Mediterranean populations of Dicentrarchus labrax. Aquat Living Resour 18: 71-76.

Loukovitis D, Sarropoulou E, et al. 2011. Genetic variation in farmed populations of the gilthead sea bream Sparus aurata in Greece using microsatellite DNA markers. Aquacult Res 42: 1-8.

McGinnity P, Prodohl P, et al. 2003. Fitness reduction and potential extinction of wild populations of Atlantic salmon, Salmo salar, as a result of interactions with escaped farm salmon. P Roy Soc Lond B Bio 270: 2443-2450.

McGinnity P, Stone C, et al. 1997. Genetic impact of escaped farmed Atlantic salmon (Salmo salar L.) on native populations: use of DNA profiling to assess freshwater performance of wild, farmed, and hybrid progeny in a natural river environment. Ices J Mar Sci 54: 998-1008.

Miller SA, Dykes DD, et al. 1988. A simple salting out procedure for extracting DNA from human nucleated cells. Nucleic Acids Res 16: 1215 .

Naciri M, Lemaire C, et al. 1999. Genetic study of the Atlantic/ Mediterranean transition in sea bass (Dicentrarchus labrax). $J$ Hered 90: 591-596.

Norris AT, Bradley DG, et al. 1999. Microsatellite genetic variation between and within farmed and wild Atlantic salmon (Salmo salar) populations. Aquaculture 180: 247-264.

Pritchard JK, Stephens M, et al. 2000, Inference of population structure using multilocus genotype data. Genetics 155: 945-959.

Ramasamy RK, Ramasamy S, et al. 2014. Structure Plot: a program for drawing elegant Structure bar plots in user friendly interface. Springerplus 3: 431.

Raymond M, Rousset F. 1995. Genepop (Version-1.2) - Populationgenetics software for exact tests and ecumenicism. $J$ Hered 86 : 248-249.

Reed TE, Prodohl P, et al. 2015. Quantifying heritable variation in fitness-related traits of wild, farmed and hybrid Atlantic salmon families in a wild river environment. Heredity (Edinb) 115: 173-184.

Rossi AR, Perrone E, et al. 2006. Genetic structure of gilthead seabream, Sparus aurata, in the central Mediterranean sea. Cent Eur J Biol 1: 636-647.

Sawayama E, Nakao H, et al. 2019 Identification and quantification of farmed red sea bream escapees from a large aquaculture area in Japan using microsatellite DNA markers. Aquat Living Resour 32, 26.

Segvic-Bubic T, Arechavala-Lopez P, et al. 2018. Site fidelity of farmed gilthead seabream Sparus aurata escapees in a coastal environment of the Adriatic Sea. Aquacult Env Interac 10: 21-34. 
Segvic-Bubic T, Lepen I, et al. 2011. Population genetic structure of reared and wild gilthead sea bream (Sparus aurata) in the Adriatic Sea inferred with microsatellite loci. Aquaculture 318: 309-315.

Skaala O, Besnier F, et al. 2019. An extensive common-garden study with domesticated and wild Atlantic salmon in the wild reveals impact on smolt production and shifts in fitness traits. Evol Appl 12: $1001-1016$.

Skaala O, Hoyheim B, et al. 2004. Microsatellite analysis in domesticated and wild Atlantic salmon (Salmo salar L.): allelic diversity and identification of individuals. Aquaculture 240: 131-143.

Somarakis S, Pavlidis M, et al. 2013. Evidence for 'escape through spawning' in large gilthead sea bream Sparus aurata reared in commercial sea-cages. Aquacult Env Interac 3: 135-152.
Souche EL, Hellemans B, et al. 2015 Range-wide population structure of European sea bass Dicentrarchus labrax. Biolog J Linn Soc 116 : 86-105.

Tine M, Kuhl H, et al. 2014. European sea bass genome and its variation provide insights into adaptation to euryhalinity and speciation. Nat Commun 5: 5770.

Vandeputte M, Gagnaire PA, et al. 2019. The European sea bass: a key marine fish model in the wild and in aquaculture. Animal Genet 50: 195-206.

Yang L, Waples RS, et al. 2019. Life history and temporal variability of escape events interactively determine the fitness consequences of aquaculture escapees on wild populations. Theor Popul Biol 129: 93-102.

Cite this article as: Polovina E-S, Kourkouni E, Tsigenopoulos CS, Sanchez-Jerez P, Ladoukakis ED. 2020. Genetic structuring in farmed and wild Gilthead seabream and European seabass in the Mediterranean Sea: implementations for detection of escapees. Aquat. Living Resour. 33: 7 